\title{
Lygia Clark: os limites do corpo generificado na série Roupa-corpo-roupa
}

Flavia Jakemiu Araujo Bortolon

Douturanda, Universidade Federal do Paraná - UFPR / flaviabortolon@gmail.com Orcid: 0000-0001-8477-2259//http://lattes.cnpq.br/9615477863886420

Enviado 06/06/2018 / Aceito 03/09/2018. 


\title{
Lygia Clark: os limites do corpo generificado na série Roupa-corpo- roupa
}

\begin{abstract}
RESUMO
O artigo pretende debater as questões dos limites do corpo, conforme a proposta da artista plástica brasileira Lygia Clark, explicitada em suas obras sensoriais (1965 - 1969). Para tal fim, foi realizada uma pesquisa documental em textos de críticos de arte, jornais e cartas da artista desde o período de sua produção até exposições mais recentes. 0 corpo passou a fazer parte da sua obra, possibilitando o questionamento das sensações que são impostas por instrumentos (objetos sensoriais) e por espaços onde se inserem. A obra desses artistas passou a questionar não somente o que é arte, mas também o local onde essas peças podiam ser apresentadas. Leitora do filósofo Merleau-Ponty, Clark propunha experiências fenomenológicas, participativas, que não deixavam o espectador passivo perante os movimentos do objeto e do corpo. Assim, Lygia Clark posicionou-se diante dos limites sensoriais e éticos do corpo, da interação entre corpo e obra por meio da problematização, ou mesmo, da inversão de performances generificadas. Sendo assim, o presente artigo tem por finalidade apresentar uma análise acerca das etapas iniciais do processo de desenvolvimento de produtos de modavestuário.
\end{abstract}

Palavras-chave: Lygia Clarck; obras sensoriais; gênero. 


\title{
Lygia Clark: the body of the genre boundaries in Roupa-corpo-roupa series
}

\begin{abstract}
The article aims to discuss the body's limits of issues as proposed by the Brazilian artist Lygia Clark, through its sensory works (1965/1969). To this end, a documentary research on art critics texts was held, newspapers and letters of the artist during the period of its production to more recent exhibitions. The body became part of the work, allowing the questioning of sensations that are imposed by instruments (sense objects) and areas where they operate. The work of these artists began to question not only what art is, but also where these pieces could be displayed. Reader of Merleau-Ponty philosopher, Clark proposed phenomenological, participatory experiences, which did not allow the passive spectator before the subject's movements and body. Thus, Lygia Clark stood before the limits, sensory and ethical body, the interaction between body and work through questioning or even reversal of gendered performances.
\end{abstract}

Keywords: Lygia Clarck; sensory works; gender. 


\section{LYGIA CLARK: DAS SUPERFÍCIES MODULARES AO CORPO}

Lygia Clark nasceu em 23 de outubro de 1920 em Belo Horizonte como Lygia Pimentel Lins, pertencente a uma família de juristas e donos de imobiliárias da capital mineira que não tinham convívio com as artes. Ao concluir seus estudos casou-se aos 18 anos com o engenheiro igualmente rico, Aluísio Clark, com o qual viveu 10 anos em sua cidade natal e teve três filhos. Em 1947, Lygia Clark mudou-se com a família para o Rio de Janeiro para estudar com Roberto Burle Marx e Zélia Salgado, ambos paisagistas e professores de arte.

Em 1953, de acordo com Ferreira Gullar, entre os artistas presentes no movimento concreto brasileiro, havia destaque para Lygia Clark e sua obra, que começava a apresentar características estilísticas e propensões filosóficas:

Podia-se ver que, àquela altura a arte brasileira padecia de dois exageros contraditórios: da parte carioca - um Serpa, Um Carvão - certo desinteresse pela indagação de alguns problemas básicos da estética concretista; da parte dos paulistas, a exacerbada intenção de tudo formular e de trabalhar segundo essa formulação prévia. Já aí, dois artistas, pelo menos, mantinham-se a salvo desses exageros: Lygia Clark e Franz Weismann. A primeira apresentava superfícies moduladas, onde já afirmava a sua posição nova, revolucionária em face dos problemas colocados pela estética bilina. Weissmann, menos impetuoso, impunha a suas obras uma coerência e uma economia de estrutura que não partiram de um a priori estético, mas de um sentido profundo da forma espacial. A posição desses dois artistas - e principalmente a experiência radical e continuada de Lygia Clark - já definiam o caminho que iria tomar a arte concreta no Brasil com a formação, em 1959, do Grupo Neoconcreto (GULLAR, 1985, p. 229).

Gullar pretende, com essa afirmação, diferenciar os trabalhos de dois artistas - Franz Weismann e Lygia Clark dos demais participantes, que tendiam a discutir questões 
unicamente artísticas ou estéticas da forma e ignoravam, apenas seguindo uma fórmula preexistente, a chegada de artistas internacionais no Brasil. O poeta e crítico afirma ainda que Lygia Clark abriu novas expectativas para a arte concreta quando enfocou o quadro como um todo orgânico, significativo, no qual a moldura não era o limite onde terminaria a obra (GULLAR, 1985).

O grupo passou a denominar-se Neoconcretista, um neologismo aceito por todos os integrantes, que se reafirmam com o Manifesto Neoconcreto. Segundo Gullar (2007), nessa fase os artistas nacionais, encabeçados por Lygia Clark, dão passos que artistas da vanguarda europeia não realizaram em suas discussões sobre o quadro e a tela, e não somente o agir sobre a tela. Continuando seus estudos em Superfícies Modulares e Contra-relevos (1959) (figura $1)$, as placas pretas e brancas parecem saltar do quadro dando uma nova percepção conforme quem as visualiza. Dentro das questões artísticas postas nas questões modulares, Lygia Clark decreta "que a pintura chegara ao fim de sua trajetória, enquanto representação, afirma a morte do plano como suporte da expressão" (CLARCK apud MILLIET, 1992, p. 52)".

Figura 1: Superfícies modulares, Lygia Clark, 1959.

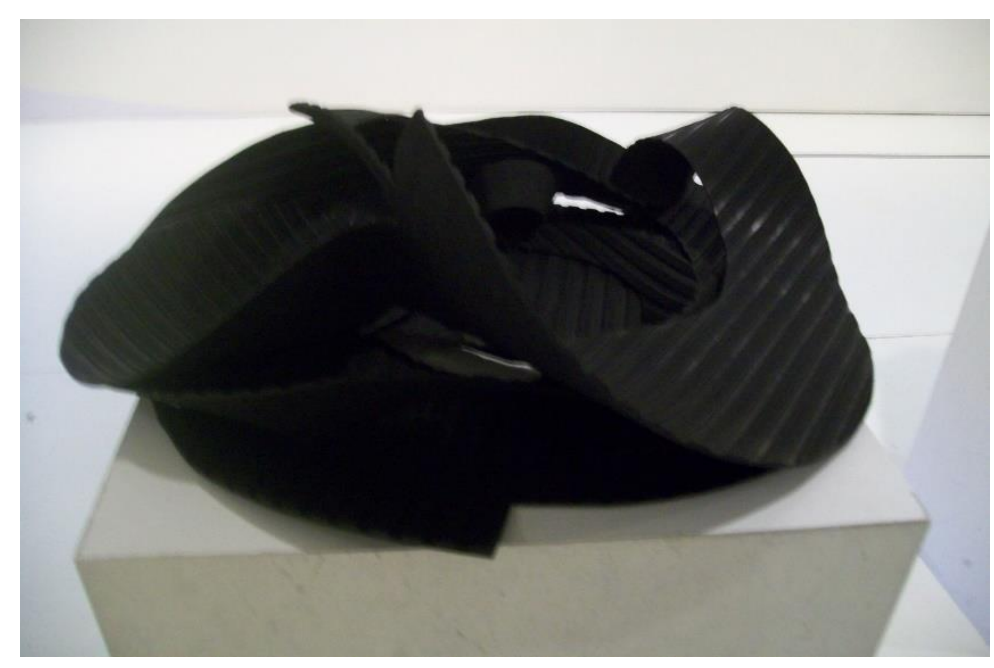

Fonte: Exposição Lygia Clark no Itaú Cultural, São Paulo, 2011. 
Em 1959, a obra Casulo marca a passagem definitiva da artista da pintura para a escultura, porém a forma ainda está presa à parede, a uma superfície plana, alcançando mais liberdade plástica com a famosa série, posterior ao neoconcretismo, Os Bichos.

A obra Bichos (1960) é composta por duas placas sobrepostas subdivididas e articuladas por dobradiças. A obra rompeu com a "tradição escultórica em vigor no século XIX porque: livres de pedestal abandonam a monumentalidade e a fixação a um local, não constituem massas e sim estruturas estereométricas construídas com material industrializado" (MILLIET, 1992, p. 67).

Bicho é uma designação metafórica, como o nome casulo, que de fato designam a busca de soluções para o problema da contradição figura-fundo, pintar ou não pintar. Os casulos, como os Bichos, nascem da opção compulsiva de Lygia Clark ao trocar o gesto simbólico do pintor pela ação real sobre o suporte da pintura. Desse modo, assim os Casulos são modificação que tornaria tridimensional a tela bidimensional, os Bichos são desdobramento deste processo de transmutação (destruição) do suporte da pintura. Noutras palavras: como não era mais possível pintar, como não podia mais dar à tela seu uso tradicional, ela a destrói para continuar a fazer arte. (GULLAR, 2007, p. 58).

A série Bichos passa, portanto, a proporcionar experiências motoras ao público: "Contemplamo-la agora, não mais como uma coisa exterior a nós, mas como um produto também de nosso esforço, de nossa ação: a obra torna-se, até certo ponto, também obra nossa" (GULLAR, 1985, p. 253). A série permitia a apropriação da obra pelo público através da experiência tátil. Lygia Clark escreve sobre essa relação do público com a obra: "O que se produz é uma espécie de corpo a corpo entre duas entidades vivas" (CLARK, 1980, p. 17). Em outra declaração, complementa: "Quando me perguntam quantos movimentos o bicho pode efetuar, eu respondo "Não sei nada disso, você não sabe nada disso; mas ele, ele sabe". (CLARK, 1980, p. 17). 
Para Clark, as esculturas atingiam os participantes, que movimentavam as dobradiças e criavam e recriavam novas formas por meio do caráter simbólico do objeto, o manuseio e a interação davam a esses participantes a sensação de construtores da arte.

Figura 2: Bichos, Lygia Clark, 1960.

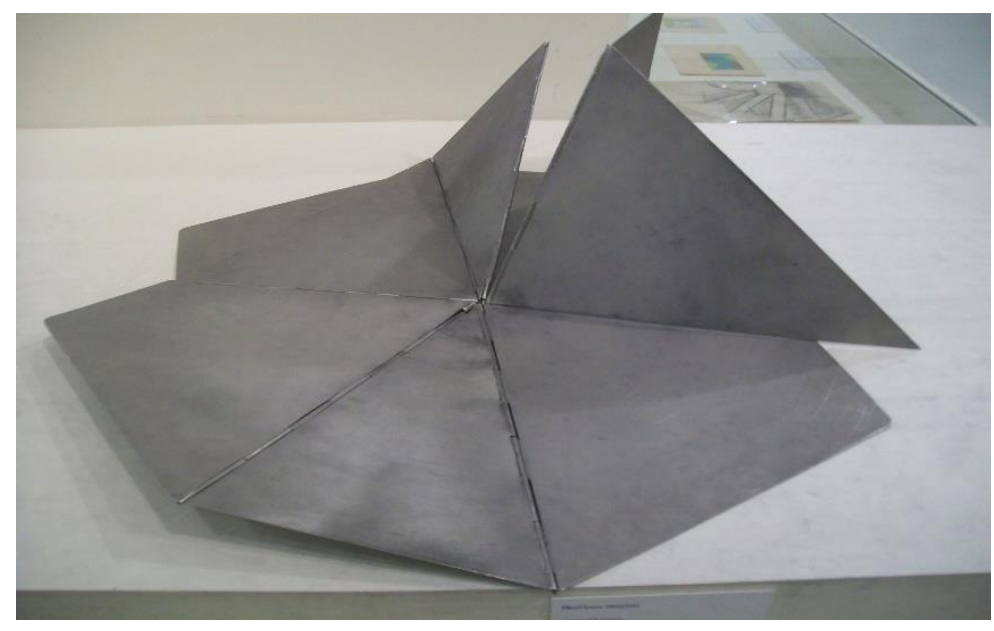

Fonte: Exposição Lygia Clark no Itaú Cultural, São

Paulo, 2011

Por volta de 1964, Lygia Clark se voltou para a ampliação sensorial do público com a obra Caminhando, na qual o papel do artista é mesclado com os participantes, que interagem na construção do objeto, da obra em si. A partir de então, ela se classifica como não artista graças ao privilégio dado à atuação de seu público, que construirá uma nova obra de arte por meio de suas sensações.

$\mathrm{Na}$ faixa de papel denominada Moebius, Clark também tem a intenção de que, ao cortá-la, o sujeito percorra um espaço contínuo que não apresente frente, verso, avesso ou direito; não há ali um ponto de partida e outro de chegada; não existe um fim previamente determinado para o qual devamos seguir (Milliet, 2009). Caminhando é uma instrução gráfica composta por várias imagens: as de um corpo sentado cujas mãos cortam e recortam a fita de papel que se alonga, afina-se e embaraça-se no colo da mulher da 
tesoura: 'espaço-tempo novo, concreto' (CLARCK, 1980, p. 25)".

Nas obras anteriores a Caminhando, o artista e a obra ainda precisavam existir para que a experiência artística ocorresse. Nessa nova proposta, qualquer pessoa poderia vivenciar uma obra com apenas um pedaço de papel e uma tesoura comum, não fabricados para um fim artístico. Clark brinca com a ideia de não ser artista, querendo induzir à conclusão de que a sua presença ou de qualquer outro artista não é mais necessária para a construção de Caminhando. Anteriormente, Clark desmaterializava a obra; agora, desmaterializa a existência do artista para construir e explorar o sujeito não artista.

Figura 3: Caminhando, Lygia Clark, 1963, Repórter de Isto é reencena Caminhando.

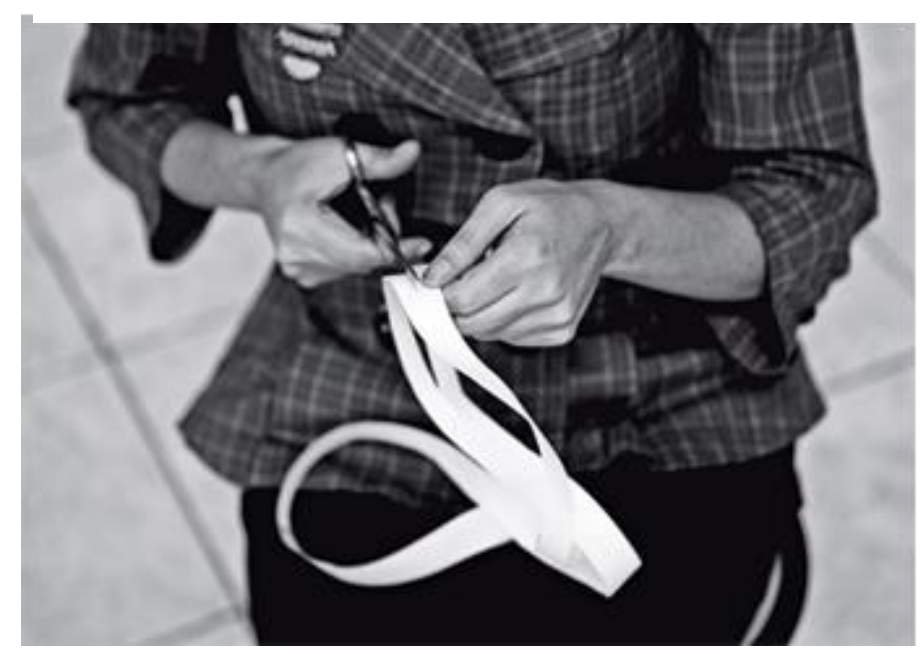

Fonte: retirada da lista da Bienal.

Em 1964, o governo francês concede a Lygia Clark uma bolsa de estudos de seis meses. Na França, a artista teve a oportunidade conhecer obras e movimentos que ocorriam na Europa, além de fazer contatos com outros artistas e galerias. Por intermédio do artista brasileiro Sérgio Camargo, Clark expôs em Sttutgart e fez contatos para realizar uma exposição individual em Londres, na Galeria Signals (CARNEIRO, 2004, p. 196). Em 1965, a exposição londrina foi amplamente divulgada. 
A partir de 1966, aproximadamente, poderíamos dizer que Clark deu origem a uma nova fase em sua trajetória artística, marcada pela busca por uma nova percepção do corpo e da própria corporalidade do ato criativo por meio de objetos e exercícios de sensibilização - a denominada "nostalgia do corpo".

Como se percebe, a proposta de sensibilização do corpo e do sujeito surge depois de Lygia Clark ter dissolvido o objeto de arte em favor do ato. De acordo com Rivera, "Caminhando radicaliza ainda mais a proposta de participação do outro na obra. Clark chega a abandonar os termos 'obra' e 'objeto' de arte em prol do termo 'proposição', acentuando o seu caráter de apelo ao sujeito" (RIVERA, 2013, p. 144).

E A primeira "proposição" a esse respeito, realizada em 1966, ocorre quando Lygia Clark percebe o tato da mão dentro de uma luva plástica com objetos externos. Denominada Pedra e Ar, essa proposta marca o início da série Nostalgia do Corpo, uma experiência sensorial. Lygia Clark descreve essa experiência:

Arranquei o saco plástico, o enchi de ar e o fechei com o elástico, e sobre ele coloquei uma pequena pedra... comecei a apalpar o saco sem me preocupar... com a pressão a pedra subia e descia por cima da bolsa de ar.... mimetizando assim um parto muito inquietante... então de repente percebi que aquilo era uma coisa viva. Parecia um corpo. Era uma corpo... isso me transformou e ao mesmo tempo significou o fim de minha crise. (CARNEIRO, 2010, p. 103).

Havia uma crise compartilhada pelos artistas, incluindo Lygia Clark e Hélio Oiticica, que buscavam uma possibilidade de resolução, isto é, a resposta para uma nova forma de arte experimental que respondesse às expectativas da vanguarda brasileira e às propostas divulgadas em manifestos e exposições. 
A série sensorial corporal seguiu com as seguintes obras: Roupa-corpo-roupa (1967), O eu e o tu (1967), Cesariana (1967) e a instalação A casa é o corpo (1968), junto a As máscaras sensoriais. Cada um desses trabalhos possui formas diferentes de estimulação corporal: o primeiro consiste em um macacão de plástico que propõe a troca das dualidades do corpo masculino/feminino, com sacos plásticos e pelos dentro de cada vestimenta, o que proporciona a troca do lugar de sensibilidade para os participantes. Também permite ver de formas diferentes, como as Máscaras sensoriais, que aguçavam as percepções dos indivíduos que as vestissem, pelos sentidos: os cheiros, os sons e a visão, por meio de óculos integrados que causavam uma distorção do mundo percebido pelo sujeito. Há ainda possibilidade sensorial da gravidez, de poder abrir a barriga e retirar o objeto, podendo abraçá-lo, como ocorre em Cesariana (ver figura 4). Assim, cada participante interfere na obra, que também o impacta, conforme as experiências simbólicas criadas na imaginação e nas lembranças.

Figura 4: Cesariana, Lygia Clark, 1968.

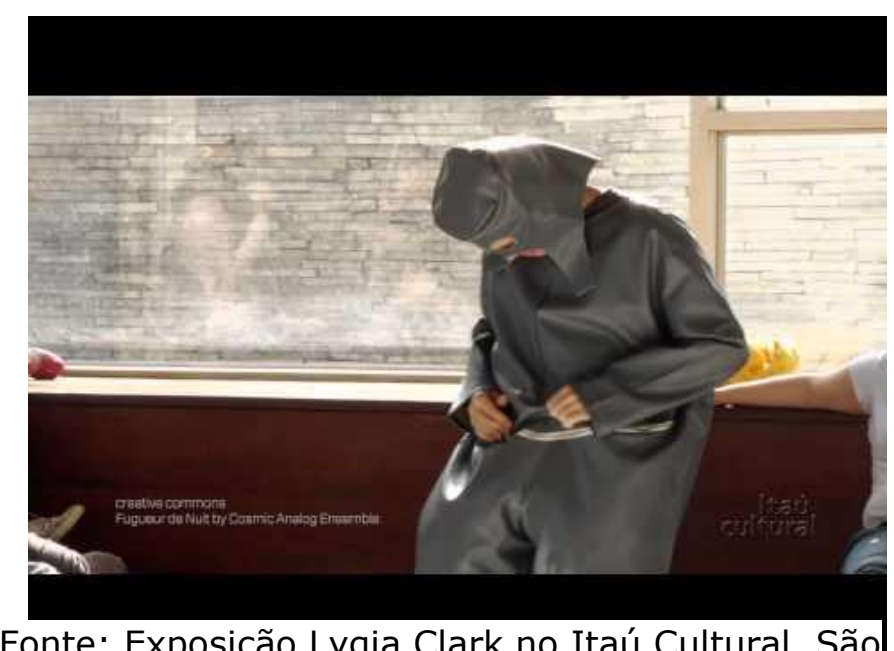
Paulo, 2011 
A instalação A casa é o corpo foi exposta na Bienal de Veneza, em 1968, na retrospectiva de 10 anos de trabalhos de Lygia Clark. Era uma estrutura de oito metros de comprimento, com dois compartimentos laterais. O centro desta estrutura se constituía por um grande balão de plástico. Os compartimentos eram divididos em: penetração, ovulação, germinação e expulsão. As pessoas que cruzavam os ambientes tinham sensações táteis ao tocar as paredes, com as luzes e a transparência do plástico e o desequilíbrio ao andar.

Seria seu corpo sua casa, como parece defender Lygia Clark com seus A casa é o corpo e O corpo é a casa? Não, no corpo o sujeito está um tanto desconfortável. Não há coincidência entre eu e meu corpo. Isso é o que a linguagem comum acentua todos os dias, quando dizemos "eu tenho corpo", mais do que "sou um corpo." (RIVERA, 2013, p.23).

A casa é o corpo apresentou como proposta despertar nos participantes a ideia de interação do corpo com a obra de arte, por meio das peças de vestuário que modificavam as sensações corporais, das máscaras que distorciam a audição, a visão e o olfato, bem como as luvas que se mexiam com o tato. Dessa forma, o sujeito era retirado do seu conforto habitual para, propositalmente, questionar o que considerava real.

Ao voltar ao Brasil em 1976, após lecionar em Paris, a artista convida um grupo de terapeutas para trabalhar com ela e com os seus participantes, agora pacientes de suas obras sensoriais. A técnica consistia em fazer o paciente viver/reviver um momento que ficou gravado na sua memória corporal por meio de um objeto com o qual tenha entrado em contato. Por exemplo, conforme Milliet (1992), a artista persiste na dialética entre o dentro e o fora, o sujeito e o objeto, o real e o imaginário, a linguagem e a nãolinguagem, através dos quais o corpo deve substituir a fala. 


\section{LYGIA CLARK EM BUSCA DO CORPO GENERIFICADO NA SÉRIE ROUPA-CORPO-ROUPA}

A partir da segunda metade da década de 1960, Lygia Clark, parcialmente em consonância com algumas das principais discussões da vanguarda nacional, dedicou-se a explorar o corpo como plataforma poética, num período de intensa atividade criativa e até mesmo expositiva. Roupacorpo-roupa foi criada por Lygia Clark em 1967, juntamente à obra A casa é o corpo, exposta pela primeira vez no Brasil no Museu de Arte Moderna, no Rio de Janeiro. Essa obra era composta por duas peças de vestuário: dois macacões trajados por um homem e uma mulher para possibilitar a experiência de estar dentro do corpo de outro sexo. A dualidade masculino/feminino estava presente na metáfora construída pela série Roupa-corpo-roupa e na obra $\mathrm{O}$ eu e o tu, em que dois macacões de plástico traziam elementos que propiciavam sugestões de corpos masculino ou feminino, com aberturas para que um pudesse tocar o outro, como na descoberta do sexo.

Consiste em macacões de plástico para serem vestidos por um homem e uma mulher. No interior dos macacões, há um forro com diversos materiais como sacos plásticos cheios de água, espuma vegetal e borracha, no sentido de dar ao homem uma sensação feminina e à mulher uma sensação masculina. Um capuz também de plástico impossibilita a visão dos participantes, e um tubo de borracha, como um cordão umbilical une os dois macacões. Seis zíperes em diversos locais da roupa permitem que, ao abri-los, os participantes explorem o outro pelo tato "o homem reconheceria o seu próprio corpo através de sensações tácteis operadas sobre objetos exteriores a ele", dizia Lygia Clark. (COSTA, 2010, p. 57).

O corpo vestido com Roupa-corpo-roupa passava a conduzir novas reações do participante, pois as relações com o mundo externo ocorrerem com a interferência da peça da indumentária. Oliveira (2008) aponta para importância da 
relação geral do corpo com o vestuário, afirmando que as aparências do corpo vestido podem ser tomadas como alicerces de construções identitárias.

Nos palcos de exposição do sujeito, integram a cena não somente os modelos prescritos de corpo, mas também os prescritos para a indumentária, e os tipos de articulação, que o sujeito realiza no processamento do corpo vestido, vão talhar a construção de sua aparência, no qual intervém a sua concepção de mundo, vida seus anseios e seus valores. (OLIVEIRA; CASTILHO, 2008, p.94).

Assim, a relação do corpo com o vestuário estaria ligada à definição da aparência, da identidade e dos valores que expressam um determinado conteúdo para os demais corpos.

Como é essa relação do corpo à roupa? E da roupa ao corpo? Mais um tipo de empréstimo? Um toma-lá-dá-cá de sistema em relação ao outro, mas em função do quê? Não haveria uma dimensão além da unilateralidade relacional que operaria por uma reversibilidade de papéis e, assim, tanto a roupa faria empréstimos, doações ao corpo, como também o corpo à roupa? O que animariam essas operações de trocas? Estariam elas restritas a valores prático-funcionais? Interfeririam os valores simbólicos? $\mathrm{E}$ os valores estéticos, como estão investidos tanto no corpo quanto na roupa? (OLIVEIRA; CASTILHO, 2008, p.94).

A interação do corpo com a roupa ocorre por meio de uma relação não unilateral. A relação primária funcional, de proteção contra o ambiente, não é a única estabelecida com os corpos. Por meio da roupa há também fatores simbólicos e estéticos. Nas peças de Lygia Clark, o vestuário ultrapassa a função estritamente utilitária para abranger a própria concepção do corpo que se "veste". Todavia, a exploração de gêneros, que ocorre dentro de algumas peças da artista, por vezes se dá de forma aparentemente assexuada. Nesta obra, por exemplo, temos macacões sem distinção externa de feminino ou masculino, nos quais os órgãos que diferenciam os sexos estão sendo "sentidos" ou evocados apenas no interior da peça. 
Para a concretização da obra, era necessário que houvesse a presença de um homem e uma mulher, para que cada um pudesse vestir um macacão com os preenchimentos que davam a sensação do corpo oposto: homem-mulher, mulher-homem. Essa necessidade vinha da proposta de Lygia Clark de alterar a percepção do sexo, uma pretensa inversão de gênero. Havia uma tensão sexual na proposta, percebida ao tocar um corpo ao mesmo tempo em que o sujeito estava dentro de outro corpo, cujo sexo era diferente. Ambos estavam ligados a um cano, que agia como um cordão umbilical e propunha a interação entre esses corpos, como questões de nascimento, melhor desenvolvida em outras ocasiões. Os participantes tinham a sensação de cegueira, pois estavam com os olhos cobertos pelo capuz, eles necessitavam do tato para tocar o seu corpo e o do outro, para conhecer a si mesmo e o sujeito a seu lado por ideias falsas, causadas pela troca de sexo, essa percepção apontava para os limites impostos pelo corpo para o conhecimento real dos fatos, neste caso, o sexo.

Figura 5: O eu e o tu, Lygia Clark, 1967.

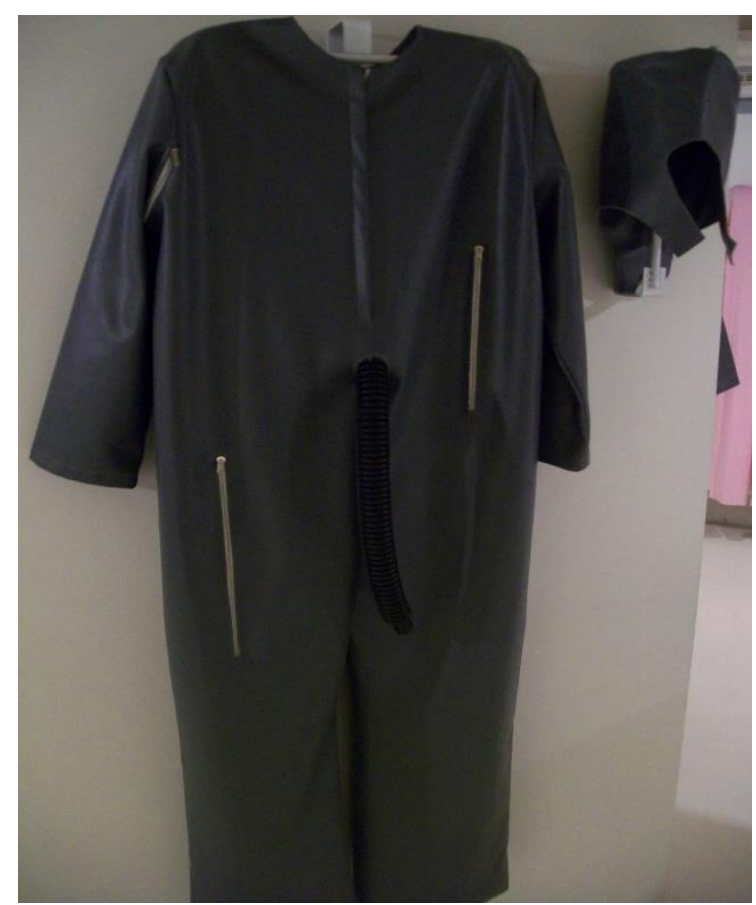


A imagem acima mostra a Roupa-corpo-roupa em exposição, sem a presença dos participantes. Pode-se observar os detalhes externos do macacão, como os zíperes, a densidade do material que ele foi confeccionado e o capuz a seu lado, que cobria os olhos e as orelhas.

Na proposta do Eu e o tu, temos um casal que veste um macacão feito de plástico, com aspecto oleoso a peça possui aberturas feitas com zíperes, o rosto do sujeito permanece coberto. O corpo impossibilita a visão e a audição, (pela cobertura dos olhos e das orelhas), um tubo de borracha na altura do umbigo interliga ambos. A intenção de Clark é que

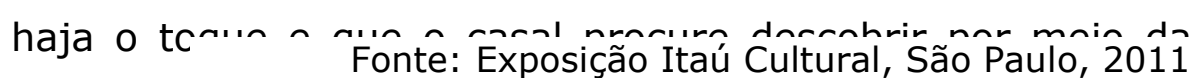
sensação das maos o corpo do outro. tm cada roupa na enchimentos que determinam a distinção sexual, porém há uma inversão, como, por exemplo, a presença de pelos no peito feminino. Lygia gerava o questionamento do corpo, do que é um corpo feminino e/ou masculino.

Trata-se de uma relação estrutural (homológica e não analógica). Meu trabalho não está longe da violência sexual porque libera instintos reprimidos, mas não está forçosamente ligado ao prazer. Tudo depende, logicamente, dos participantes: o erotismo pode ser negado em favor do lúdico, e vice-versa. (Clark, 1998, p. 232).

A sensibilidade dos gêneros como fixos é questionada por Lygia Clark por meio das sensações corporais modificadas com as roupas/obras. A sensação provocada pelos pesados macacões não era então somente o tocar-se e o descobrir o outro, ademais, era de ser invadido, aberto pelo outro, e, ao mesmo tempo, poder fazer o mesmo. No texto Breviário do corpo a artista remonta à sensação do tocar e descobrir o sexo, descrevendo como ele poderia ser percebido por meio 
dos toques-cegos causados pelas indumentárias do Eu e o tu.

Figura 6: Detalhe de O eu e o tu, Lygia Clark, 1967

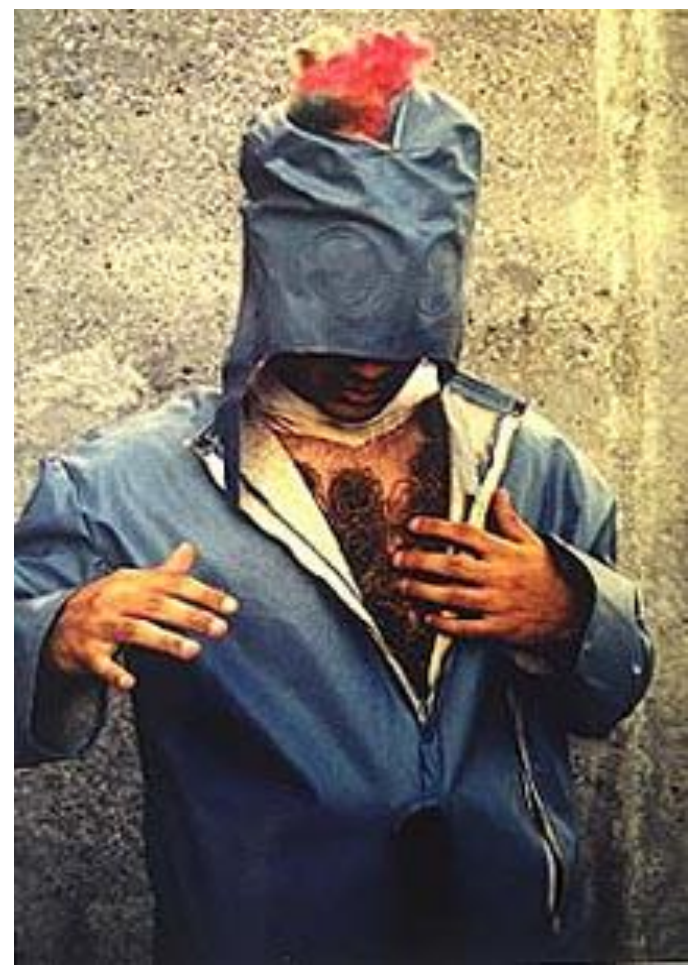

Fonte: Imagem organização Mundo Lygia Clark, 2004

Mas que tiveram também a sabedoria da espera e por um pequeno lapso de tempo compreenderam que, se elas podiam destruir com tal desejo e violência, poderiam também reconstruir este corpo composto de uma cabeça alienada, de um coração frouxo, de um sexo calado, rancoroso e surdo. Mãos que andaram nesta ocasião pelo meu corpo, como um carrinho de mão, medindo- o, analisando-o, afagando-o e trazendo até o meu conhecimento todas as necessidades deste corpo até então inerte e morto. Mãos que passaram pela minha sensualidade como um arado, desdobrando, revolvendo, remexendo, mãos que arrumaram minha cabeça como uma grande gaveta em desordem. (CLARK, 1980, p.116).

Como na imagem, que mostra o detalhe da parte de dento do macacão, o participante está descobrindo o corpo por meio do toque, Clark descreve poeticamente essa descoberta por meio do tato na citação acima, essas mãos 
ao tocar provocam sensações e auxiliam a formular um conceito sobre o eu.

Na matéria de capa da revista Visão, de 28 de abril de 1967 - com o cabeçalho Novas tendências da arte, o título da matéria A louca arte dos nossos jovens artistas, escrita pelo crítico de arte Flávio de Aquino (figura 9) a respeito da exposição que apresenta a série Roupa-corpo-roupa, no Museu de Arte Moderna no Rio de Janeiro, em 1967 -, o jornalista comenta como foi o contato do público/participante com a obra. Dentro da compreensão do crítico, as novas experiências artísticas, entre elas a obra de Lygia Clark, rompem com antigos conceitos de "arte": "Hoje podemos afirmar que um capítulo da história da arte se encerrou e iniciou quando entraram em cena os rudes, atrevidos e mal trajados jovens da pop-arte (AQUINO, 1967)." Sobre Lygia Clark, Flávio Aquino escreve:

A mesma artista, em sua roupa-corpo-roupa coloca um casal ao vivo, frente a frente vestido com macacão de plástico fendido por inúmeros fechos éclair. Começada a representação, macho e fêmea desenvolvem um lento ritual mímico, no qual mutuamente descobrem que um é o outro, ou seja, que homem e mulher só existem porque se completam. Ligia nega que isso é um ballet $\mathrm{e}$ também afirma que "uma vez completado o ato da criação artística o resultado para mim é indiferente. Detesto rever o que faço minha casa não é decorada com minhas obras. (Aquino, 1967. p. 24).

Figura 7: Lígia nega que sua experiência seja um ballet. Revista Visão, 28 de abril de 1967.

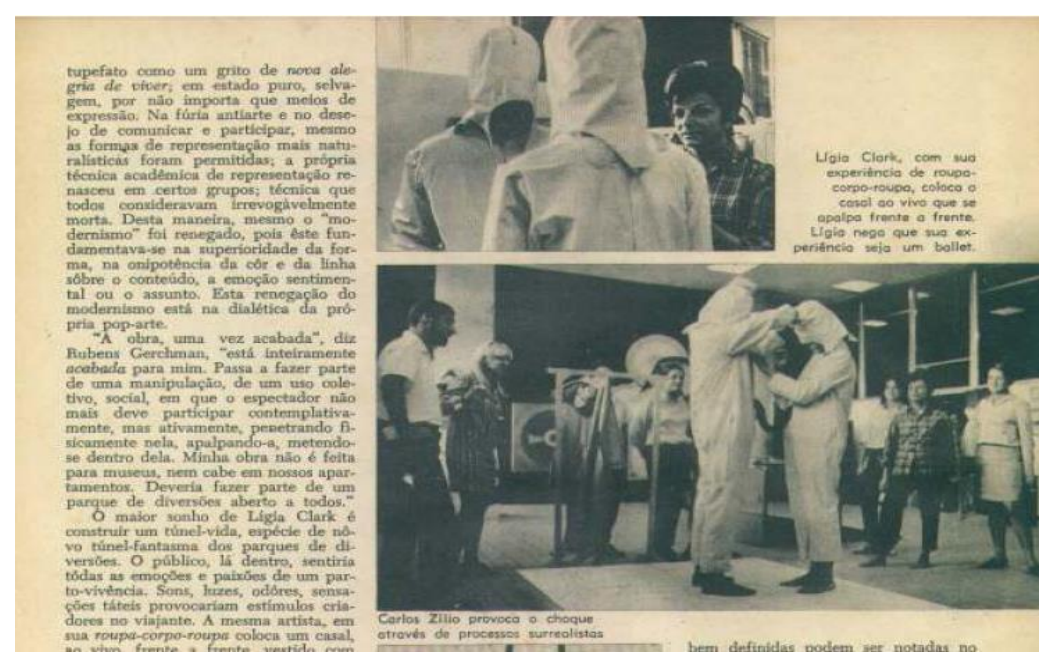


Na legenda da imagem, "Lígia nega que sua experiência seja um ballet", o conceito de experiência corporal da artista parece confuso para Aquino, pois ela traz novas proposições e questionamentos que serão feitos pelo participante ao se vestir: questionamentos sobre gênero, sobre violação e sobre a percepção do outro. Segundo Sônia Salomão Khéde (1981), a visão de alguns jornalistas entrava em conflito com a geração de vanguarda nas artes, havia o choque de

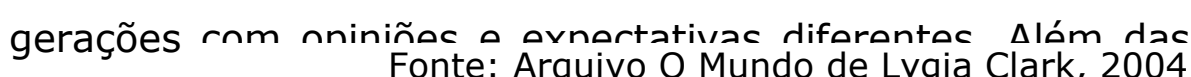
diferenças ıeouogıcas sodre arce e a aıscussao ae sexo e gênero, os vanguardistas batiam de frente com os interesses e as afirmações das autoridades do regime que se estabelecia no governo.

Através da obra Roupa-corpo-roupa, é possível compreender que o corpo do homem surge como um limite e uma completude possível para o corpo da mulher e viceversa, tal como na citação de Aquino. Assim, como em outras obras da artista, os eventuais limites de um corpo são também uma completude, uma saciedade, ainda que temporária e passageira, de um desejo, ou seja, de uma carência, de uma necessidade. Portanto, da mesma forma que antes os objetos sensoriais limitavam o corpo pela pele e pelo tato quando demonstravam a expansão do mesmo pela exploração de outros corpos (objetos, no caso), agora, com $\mathrm{O}$ eu e o tu, o limite é também uma ampliação, uma extensão, um pequeno prazer.

Em contraposição, em outra reportagem do jornal carioca O Globo, de 11 de abril de 1967, na matéria Arte jovem apresenta no MAM a nova-objetividade, Lygia Clark explica ao jornalista que em Roupa-corpo-roupa e O eu e o tu, como indumentária física, os visitantes encontraram "biótipos trocados". A série de Clark traz questões de gênero e sexo 
que estavam presentes no cotidiano dos intelectuais e artistas do final dos anos 1960, mesmo com a repressão exercida pelo governo militar. O corpo e suas sensações podem modificar a realidade percebida quando há interferências, como os enchimentos, havendo um deslocamento das percepções causadas pelos macacões.

É nesse período que a vanguarda nacional expõe e aborda a questão do corpo como um problema ético e poético. Conforme afirma Lucia Santaella (2004), muitas artes participativas no século $\mathrm{XX}$, entre as quais estão os trabalhos de Lygia Clark e Hélio Oiticica, são obras que apelam para a entrada do receptor na obra, sem o que ela não aconteceria. O corpo volta às artes como um problema a procura de respostas (Santaella, 2004). Lygia Clark escreve sobre o corpo em relação ao sexo feminino:

O corpo que no ritual se põe de joelhos, expressando assim com toda a reverência de que é possuído pelo mistério do outro corpo que a ele se oferece: pênis que num gesto soberbo de sociabilidade se transforma num braço estendido pelo prazer de encontrar o outro. O corpo que se transforma na própria vagina, para receber este gesto de entendimento do conhecimento, abrigo poético, onde o silêncio vem cheio de propostas e a escuridão e o esquecimento da autonomia do um. (CLARK, 2004, p. 123).

Trata-se, bem entendido, de um problema "ético universal". Segundo Judith Butler (2003), em Problemas de gênero, ocorre uma transformação na forma de se pensar/sentir o corpo, pois o corpo "não é um ser, mas uma fronteira variável, uma superfície cuja permeabilidade é politicamente regulada, uma prática significante dentro de um campo cultural de hierarquia de gênero e heterossexualidade compulsória" (BUTLER, 2003, p. 198).

As sensações podiam sugerir, conforme promovem os macacões de Lygia Clark, o gênero como independente do sexo, o próprio gênero como um conceito flutuante, "com a 
consequência de que homem e masculino podem, com igual facilidade, significar tanto um corpo feminino como um masculino, e mulher e feminino, tanto um corpo masculino como um feminino" (BUTLER, 2003, p. 24-25).

Judith Butler teoriza que o gênero é comunicado através de desempenhos sociais que envolvem, por exemplo, a adoção de certos estilos de vestimenta e tipos de acessórios e maquiagem, mas o eu não é inteiramente masculino ou feminino. Entretanto, no final do século $X X$, os ideais hegemônicos de comportamento e aparência de gênero apropriados ainda permaneciam bastante diferentes para cada um dos gêneros. Algo central para o conceito de hegemonia é a ideia de que as definições hegemônicas de realidade, normais e padrões parecem "naturais" e incontestáveis. (Crane, 2006, p.51).

Os pressupostos de gêneros codificados por padrões socialmente definidos como "naturais" e incontestáveis já estavam sendo questionados quando os macacões de Lygia propuseram nada menos que a inversão "cênica" dos sexos. Quando a hegemonia masculina patriarcal é contestada por meio da possibilidade de sentir-se no outro sexo, pode-se dizer que Lygia Clark introduz, em obra, a questão mais ampla da flutuabilidade dos gêneros.

O corpo não é um dado passivo sobre o qual age o biopoder, mas antes a potência mesma que torna possível a incorporação prostética dos gêneros. A sexopolítica torna-se não somente um lugar de poder, mas, sobretudo, o espaço de uma criação na qual se sucedem e se justapõem os movimentos feministas, homossexuais, transexuais, intersexuais, transgêneros, chicanas, pós-coloniais...As minorias sexuais tornam-se multidões. (PRECIATO, 2011, p. 14).

O corpo, nesses termos, não deixa de ser um questionamento sobre os regimentos sociais, morais e políticos. O corpo passa a ser ativo, a propor novas concepções de gênero, política e família, em um período com ampla censura moral exercida e imposta pelo governo militar ditatorial, censura obrigatoriamente reforçada por 
meios de comunicação. Em termos gerais, trata-se, claro, de uma questão política, ao menos se tivermos em mente o seguinte raciocínio de Stuart Hall:

Assim sendo, certamente, há práticas políticas que se referem ao controle e ao exercício do poder, da mesma forma que existem práticas econômicas, que se referem à produção e distribuição dos bens e da riqueza. Cada uma está sujeita às condições que organizam e regem a vida política e econômica destas sociedades. Agora, o poder político tem efeitos materiais muito reais $\mathrm{e}$ palpáveis. Contudo, seu verdadeiro funcionamento depende da forma como as pessoas definem politicamente as situações. Por exemplo, até recentemente, as relações familiares, de gênero e sexuais eram definidas como fora do domínio do poder: isto é, como esferas da vida nas quais a palavra "política" não tinha qualquer relevância ou significado. Teria sido impossível conceber uma "política sexual" sem que houvesse alguma mudança na definição do que consiste o âmbito "político". Da mesma maneira, só recentemente - desde que o feminismo redefiniu "o político" (como por exemplo: "o pessoal é político") que passamos a reconhecer que há uma "política da família". E isto é uma questão de significado - o político tem a sua dimensão cultural. (HALL, 1997, p. 12-13).

Figura 8: Movimentos feministas, 1969.

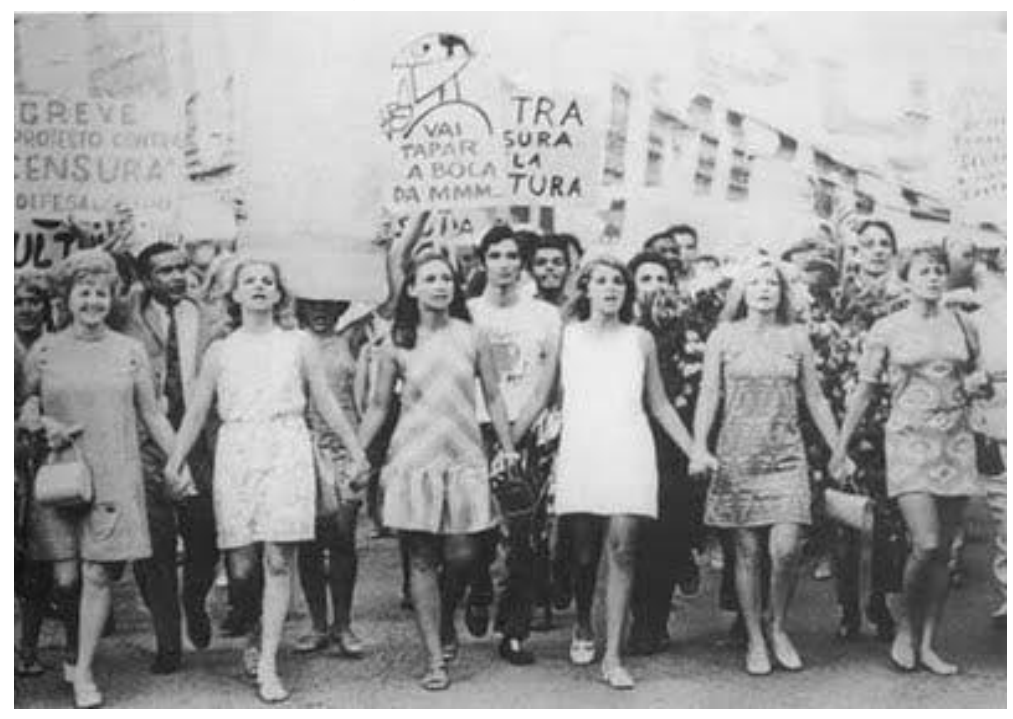

Fonte: O Estado de S. Paulo, <http://blogs.estadao.com.br/ apenas-gravida/que-filho-darei-para-o-mundo $>/$, ).

A fotografia acima mostra uma passeata em que um grupo de mulheres está à frente da manifestação pelo fim da 
censura imposta. Nesse contexto, as mulheres começam a participar das atividades que pediam liberdade, expondo-se onde antes era lugar somente masculino, exigindo direitos que eram concedidos apenas aos homens. Note-se que elas não estão buscando apenas direitos relacionados à maternidade ou ao ideal de família, mas a ações políticas.

Parte-se do princípio que, após os anos 1960/70, período o qual Hall (1997) denomina de "revolução cultural", questões que se restringiam ao espaço doméstico são levadas à discussão, à aprovação social e política. As obras da série Roupa-corpo-roupa levam a discussões que anteriormente pertenciam ao campo do indivíduo para o julgamento moral e político de uma sociedade que vivencia um regime imposto e punitivo:

Quando ele [o homem] coloca na sua cabeça um capacete sensorial ele se isola do mundo, depois de já ter se situado em todo um processo anterior no desenvolvimento da arte, nessa introversão perde contato com a realidade e encontra dentro dele mesmo toda a gama de vivências fantásticas. Seria uma maneira de buscar-lhe o fôlego da vivência. [...] 0 homem capacete tem a tendência de se desagregar no momento da vivência. Nostalgia do corpo, decepá-lo e vivê-lo em partes para depois reintegrá-lo como organismo vivo e total. (CLARK, 1975, p. 219-220).

Nessa mesma linha de se reconhecer nas possibilidades dadas a um sexo, geralmente trocando os termos homem/mulher, Lygia Clark cria Roupa-corpo-roupa: Cesariana (1967), um macacão feito do mesmo material de O eu e o tu, em que, pretensamente, os homens podem ter a sensação da cesárea. Conforme a artista escreve em carta de 1969 para o amigo Hélio Oiticica, a ideia surgiu "outro dia no banho, vendo a minha 'cesariana' tomei consciência de que foi preciso fazer a Roupa-corpo-roupa Cesariana para fazer em seguida a minha... acho que sou a mulher mais maluca do universo" (CLARK, 1996, p. 39). 
Cesariana é um macacão feito com tecido grosso emborrachado, com um capuz que cobria os olhos e orelhas. Nela se encontrava uma barriga, semelhante à de uma mulher grávida, com zíperes, permitindo que fosse aberta, e dela se podia retirar a espuma picada cor de rosa que havia dentro, como se aquele que a vestisse estivesse realizando um parto. As reações à obra foram diversas. Lygia Clark lembra-se que,

ao praticar a cesariana, as pessoas apresentam as reações mais inesperadas. Algumas levam a espuma ao rosto, outras atiram o material para o alto ou na direção dos espectadores. O crítico francês Pierre Restany chamou esse trabalho de um verdadeiro happening psíquico-dramático. (Clark, 1980. p. 38).

Figura 9: Roupa-corpo-Roupa: Cesariana, Lygia Clark, 1968

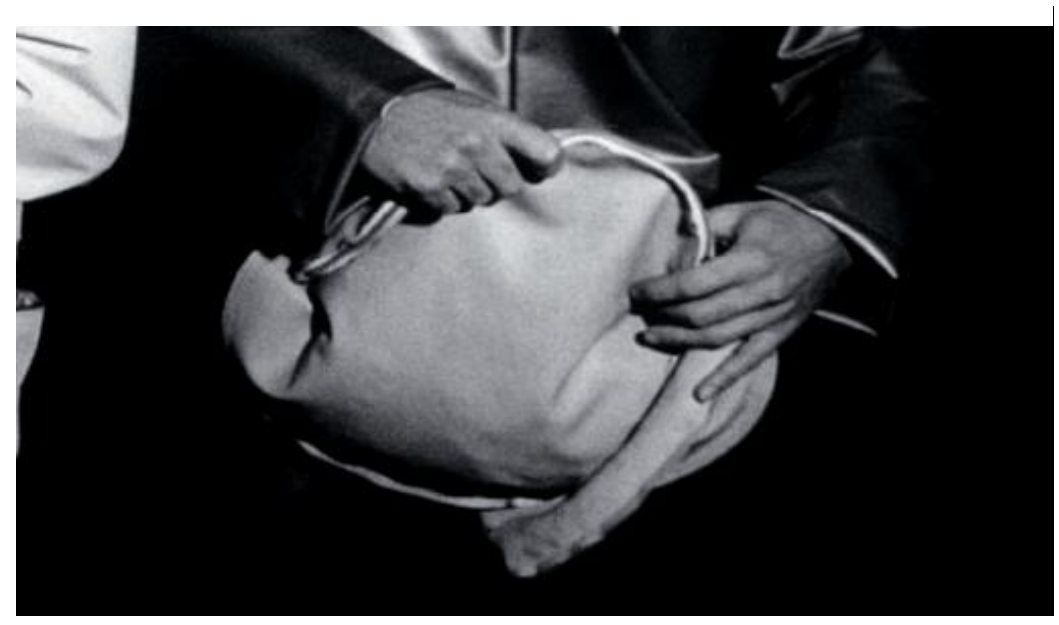

Fonte: O Mundo de Lygia Clark, 2004.

A questão de maternidade e sexo é tocada em várias cartas de Lygia Clark ao amigo artista Hélio Oiticica. Em algumas ela retoma o tema de como foi sua primeira vez, como se sentiu "deflorada", utilizando, em muitos casos, essa expressão para relatar os objetos sensoriais, a abertura dos zíperes, o toque do outro. A maternidade em Clark aparece, algumas vezes, como uma característica pesada para a mulher, como uma subjetivação da sua liberdade. Em uma carta de 1968, um ano após Roupa-corpo-roupa, ela 
descreve o ser mãe: "De mãe, nada mais tenho a dar, mesmo em relação aos meus filhos... não posso mais aceitar alguém dependente de mim"; e mais adiante: "Continuo sozinha e parece que para sempre. Isso não me deprime em nada. Por outro lado estou usufruindo numa grande alegria toda essa liberdade, longe de problemas de filhos, desse ambiente daí que às vezes vira até sufocante (CLARK, 1996, p. 83)".

Sendo o corpo uma presença na discussão da arte contemporânea, florescendo fortemente na década de 1960/70 na vanguarda nacional, ela não deixou de estar presente nas obras das artistas mulheres. Lygia Clark explorou o corpo feminino e masculino invertendo as polaridades. De acordo com Maria José Justino (2013), a mesma aura boêmia que pertencia ao artista homem não servia para a mulher artista, no homem era um charme, na mulher uma devassidão de caráter. Para quebrar esse cunho pejorativo, muitas reivindicações dos movimentos feministas eram voltadas para a maternidade, pois a associação com mulher-mãe correspondia às expectativas impostas pela sociedade.

Certamente, a arte por ser um lugar privilegiado da liberdade, vem permitindo à mulher, no seu exercício, transgredir condicionamentos e criar um olhar sobre si mesma, ao mesmo tempo que abre comunicação ao outro, às experiências coletivas, desde experiências intimistas de Lygia Clark (objetos relacionais) à comunitária Judy Chicago (feminist art program) ambas, por processos diferentes, chegando ao corpo coletivo. Para as mulheres, a arte vem se constituindo num espaço de afirmação, de reconhecimento e do exercício da alteridade. (JUSTINO, 2013. p. 5).

Através da arte sensorial, o corpo descoberto, com todas suas nostalgias, está mais liberto para agir e repensar as coerções sociais, que no momento passaram a se tornar políticas. Como propositora dessa ação por meio dos objetos sensoriais, a função passa a ser de liberdade. Para Lygia Clark, 
Isso é um exercício para a vida. Se a pessoa, depois de fazer essa série de coisas que dou, consegue viver de uma maneira mais livre, usar o corpo de uma maneira mais sensual, se expressar melhor, amar melhor... Isso no fundo me interessa muito mais como resultado do que a própria coisa em si que eu proponho a vocês. (CLARK, 2006. p. 123).

Lygia Clark propôs limites do corpo e experiência corpórea por meio das obras analisadas ( $\mathrm{O}$ eu e o tu e Cesariana). Para criar experiências, a artista fez uso de peças do vestuário, criadas e confeccionadas por ela, para que o participante, ao vesti-las, pudesse ter sensações corpóreas. As roupas funcionam, nesse momento, para Clark, como extensão do corpo ao possibilitarem o toque em objetos e limitadores, quando interferem ou criam outros conceitos do objeto ou do corpo. Ao contrário da proposta comum das peças de vestuários (conforto, proteção e caráter estético), essas peças produzidas pela artista muitas vezes limitam a mobilidade do corpo, dificultam os movimentos e as funções sensoriais (visão e tato). Outro aspecto é a relação que estabelecem com o outro, ao conectar fisicamente, por meio de canos, ou emocionalmente, como quando o sujeito abre o zíper para retirar a espuma, o que figura uma cesariana.

\section{UMA POSSÍVEL CONCLUSÃo SOBRE O CORPO NA OBRA DE LYGIA CLARK}

Lygia Clark estabelece, em seu percurso como artista, novas questões estéticas concernentes ao lugar e à relação do público com a arte, apresentando possibilidades que vão desde a retirada do quadro da parede até Casulos, Bichos, Caminhando, chegando aos Objetos Sensoriais. Embasada nos conceitos de fenomenologia corporal e da arte de Merleau-Ponty, suas obras propõem ao corpo do público a 
participação e os estímulos com objetos cotidianos para que essas sensações, fantasmáticas, tornassem-se então arte. Segundo Merleau-Ponty, o corpo possibilita estabelecer ligações com a consciência da realidade, sendo o corpo, como aponta também Nancy (2012), limitador da experiência do indivíduo com as dos demais.

Em 1966, os objetos sensoriais de Lygia Clark foram criados para tornar possível uma consciência alterada de nossos corpos, de nossas capacidades perceptivas e mesmo de nossas inevitáveis restrições físicas e mentais. Os objetos sensoriais da artista precisavam ser ativados em contato direto com o outro, em coordenação com as nossas funções corporais, orgânicas, subjetivas. Em boa parte de suas obras, Lygia Clark dava indicações de como agir e interagir com os objetos em busca de sensações que poderiam estar em meio ao corpo "fantasmático", desenvolvendo novas formas de conceber a obra de arte, tirando dos meios tradicionais o papel de única forma de arte (quadro e esculturas, por exemplo), dando ao público o poder de participar do ato criativo por meio do estimulo de objetos cotidianos sugeridos pelo propositor.

Na obra "Roupa-corpo-roupa" "O eu e o tu" de 1967, por exemplo, os sexos podiam ser alterados, o homem vestindose interiormente com órgãos femininos e a mulher experimentando algumas caraterísticas tidas como masculinas. Macacões de plástico igualmente sem definição de sexo por fora, somente com enxertos internos, provocavam a sensação de pertencer a um sexo. Era preciso tocar-se por meio de zíperes para sentir o outro e a si mesmo. Lygia Clark viabilizava uma maneira diferente da "troca" de sexo, o vestuário que simbolizava em muitos casos o gênero que ao qual pertence o sujeito (vestidos e saias como roupas relacionadas no ocidente a mulheres, bem como ternos e gravatas ao mundo masculino) aos 
observadores externos não era possível perceber o sexo dos participantes. Somente por dentro da peça (macacões de plástico idênticos) em que estavam costurados enchimentos de espuma e pelos era possível vivenciar a sexualidade de cada um. Tocando o corpo do outro notava-se o próprio sexo, já que a mulher deveria vestir o macacão masculino e vice e versa, e ao tocar-se poderiam conhecer o corpo do outro. A peça ainda trazia um cano no umbigo que conectava os participantes, como se estivessem presos a um cordão umbilical, pertencendo ou saindo do outro.

A obra proporcionava ao participante uma liberdade maior de conhecer o corpo por meio do toque, capacitando-o para agir mais livremente; segundo Lygia Clark, essa era a verdadeira intenção que a obra deveria comunicar e resultar ao público. O que Lygia Clark propunha era que o sujeito que participasse do Roupa-corpo-roupa, bem como dos outros objetos sensoriais, pudesse se redescobrir em sua própria condição (homem/mulher), e se reencontrasse com o passado pelas memórias e novas sensações (um parto para um homem, um órgão masculino para a mulher). 0 corpo em Clark aparece dentro do contexto de vanguarda; a artista não é declaradamente feminista, todavia, rompe barreiras ao apresentar o corpo, ao tocá-lo e ao questionálo.

\section{REFERÊNCIAS}

ARAÚJO, Paulo Cesar. Eu não sou cachorro, não: música popular cafona e ditadura militar. 2. ed. Rio de Janeiro: Editora Record, 2002.

BRITO, Ronaldo. Neoconcretismo: vértice e ruptura do projeto construtivo brasileiro. 2 ed. São Paulo: Cosac Naify, 1999.

a 2002. São Paulo: Cosac Naify, 2005. 
BRITO, M. da Silva. História do Modernismo Brasileiro: antecedentes da Semana de Arte Moderna. 2 ed. Rio de Janeiro: Civilização Brasileira, 1996.

BRETT, Guy. Lygia Clark: seis células. In: BASBAUM, Ricardo (Org.). Arte contemporânea brasileira: texturas, dicções, ficções, estratégias. Rio de Janeiro: Rios Ambiciosos, 2001, p. 31-53.

BORDO, R. Susan. 0 corpo e a reprodução da feminidade: uma apropriação feminista de Foucault. Gênero, corpo, conhecimento. Rosa dos Tempos: Rio de Janeiro, 1997.

BUTLER, Judith. Problemas de gênero: feminismo e subversão da identidade. Rio de Janeiro: Civilização Brasileira, 2003.

Fundamentos contingentes: o feminismo e a questão do "pós-moderno". Cadernos Pagu, Campinas, v. 11, p. 11-42, 1998.

CARNEIRO, Beatriz Scigliano. Relâmpagos com claror: Lygia Clark e Hélio Oiticica, vida como arte. São Paulo: Imaginário: Fapesp, 2004.

COSTA, Cacilda Teixeira da. Roupa de artista: o vestuário na obra de arte. São Paulo: Editora Edusp, 2010.

DUARTE, Paulo Sérgio. Anos 60: transformações da arte no Brasil. Rio de Janeiro: Campos Gerais, 1999.

Arte brasileira contemporânea: um prelúdio. Rio de Janeiro: Silvia Roesler, 2008.

FICO, Carlos. Prezada censura: cartas ao regime militar. Revista Topoi de História, Rio de Janeiro: UFRJ, P. 251-286. n. 5, set. 2002.

FREITAS, Artur. Arte de guerrilha: vanguarda e conceitualismo no Brasil. São Paulo: Edusp, 2013.

GASPARI, Elio. A ditadura envergonhada. São Paulo: Companhia das Letras, 2002.

GULLAR, Ferreira. Experiência neoconcreta: momentolimite da arte. São Paulo: Cosac Naify, 2007.

Vanguarda e subdesenvolvimento: ensaio sobre arte. Rio de Janeiro: Civilização Brasileira, 1969.

HALL, Stuart. A centralidade da cultura: notas sobre as revoluções culturais do nosso tempo. Educação \& Realidade, Porto Alegre n.2. v. 22, jul/dez.1997. 
HOBSBAWN, Eric. A era dos extremos: o breve século XX. 1941-1991. São Paulo: Companhia das Letras, 1995.

JAREMTCHUK, Daria; RUFINONI, Priscila. Arte e Política: situações. São Paulo: Editora Alameda, 2013.

JUSTINO, Maria José. Mulheres na arte. Que diferença isso faz? Curitiba: Museu Oscar Niemeyer, 2013.

. Lygia Clark, a vivência dos paradoxos. In: Cultura Visual, n. 15, Salvador: EDUFBA, p. 95-114. mai. 2011..

KHÉDE, Sonia Salomão. Censores de pincenê e gravata: dois movimentos da censura teatral no Brasil. Rio de Janeiro: Codecri, 1981. (Coleções Edições do Pasquim, v. 113).

MERLEAU-PONTY, M. Fenomenologia da percepção. Trad. Carlos Alberto Ribeiro de Moura. São Paulo: Martins Fontes, 1999.

MILLIET, Maria Alice. Lygia Clark: obra-trajeto. São Paulo: Edusp, 1992.

MORAIS, Frederico. Artes plásticas: a crise da hora atual. Rio de Janeiro: Paz e Terra, 1975.

. (Org.). Depoimento de uma geração: 19691970. Rio de Janeiro: Galeria de Arte Banerj, 1986.

PRECIADO, Beatriz. Deleuze ou l'amour qui n'ose pas direson nom. Manifeste contrasexuel. Paris: Balland, 2000.

PELEGRINI, Ana Cláudia Salvato; PECCININI, Daisy V. M. Opinião 65. Arte do século XX/XXI: Visitando o MAC na web. Módulo 4.4 Disponível em: <http://www.mac.usp.br/mac/templates/projetos/seculoxx/ modulo4/opiniao/opiniao.html> Acesso em 01/10/ 2014.

REIS, Paulo. Arte de vanguarda no Brasil: os anos 60. Rio de Janeiro: Zahar, 2006.

RIDENTE, Marcelo. Artistas e intelectuais no Brasil pós1960. Tempo Social. São Paulo, v. 17, n. 1, jun. 2005.

RIVERA, Tania. 0 avesso do imaginário: arte contemporânea e psicanálise. Rio de Janeiro: Cosac \& Naify, 2013.

ROLNIK, Suely. Subjetividade em obra Lygia Clark, artista contemporânea. Núcleo de Estudos da Subjetividade. São Paulo: PUC-SP, 2002. Disponível em: <http://www.pucsp.br/nucleodesubjetividade/Textos/SUELY/ Subjemobra.pdf >. Acesso em 1/08/ 2014. 
Arte cura? Núcleo de Estudos da Subjetividade. São Paulo: PUC-SP, 1996. Disponível em: <http:// www.pucsp.br/nucle odesubjetividade/Tex tos/SUELY /Hib rido.pdf>. Acesso em 1/08/2014.

. Lygia Clark e o híbrido arte/clínica. In: Percurso: Revista de Psicanálise. Ano VIII, n. 16. Departamento de Psicanálise, Instituto Sedes Sapientiae. São Paulo, $1^{0}$ semestre de 1996, p. 43-48. Disponível em: <http://www.caosmose.net/suelyrol nik/pdf/Artecli.pdf>. Acesso em 1/08/ 2014.

- Molda-se uma alma contemporânea: o vazio-pleno

de Lygia Clark. In: The $\mathbf{E}$ xperimental Exercise of Freedom: Lygia Clark, Gego, Mathias Goeritz, Hélio Oiticica and Mira Schendel. Los Angeles: The Museum of Contemporary Art, $1999 . \quad$ Disponível em: $<$ http://caosmose.net/suelyrolnik/pdf/molda_com_resumo.p df. $>$. Acesso em 1/08/2014.

SANTAELLA, Lucia. Corpo e comunicação: sintonia e cultura. São Paulo: Paulus, 2004.

Fontes:

AQUINO, Flávio. A louca arte dos nossos jovens artistas. In: Novas tendências da arte. Revista Visão, 28 abr. 1967.

BITTENCOURT, Francisco. A geração tranca-ruas. Jornal do Brasil, Rio de Janeiro, 09 mai. 1970.

CARS, Rosa. Arte de Lygia é o Mundo Existencial. Jornal do Comércio, Rio de Janeiro, 15 jan. 1967.

CLARK, Lygia . A Sensível Manifestação. Jornal do Brasil. Rio de Janeiro, 10 nov. 1971.

. Lygia Clark, uma arte sem consumo. O Estado de São Paulo. São Paulo: 06 fev. 1971.

A coragem e a Magia de ser contemporâneo. Correio do Manhã. Rio de Janeiro, 10 nov. 1971.

Lygia Clark e a Proposição da Imanência. Jornal do Brasil. Rio de Janeiro: 06 jan.1968.

CLARK, Lygia . OITICICA, Hélio. Cartas 1964-74. Org. Luciano Figueiredo. Rio de Janeiro: Editora UFRJ, 1998.

. Da supressão do objeto (anotações). In: FERREIRA, Glória; COTRIM, Cecília (Org.). Escritos de artistas: anos 60/70. Rio de Janeiro, Zahar, 2006. 
GULLAR, Ferreira. et al. Manifesto Neoconcreto. Jornal do Brasil, Rio de Janeiro, Suplemento Dominical, p. 4-5, 23 mar. 1959.

MAURICIO, Jayme. Lygia Clark e a proposição da imanência. Jornal do Brasil, Caderno B, 06 jan.1968.

Mary e Lygia escultoras premiadas em Paris e Salvador. Correio da manhã. 5 jan. 1967.

. Lygia e as caixas. Correio da Manhã, $2^{\circ}$ Caderno, 10 jan.1967.

PEDROSA, Mario. A Crise brasileira e o movimento: Opinião, opinião, opinião. Correio da Manhã, Caderno 4, p. 3, 11 set. 1966 .

. Os deveres do crítico de arte na sociedade. Correio da manhã, 10 jul. 1969.

Significação de Lygia Clark. Jornal do Brasil. Rio de Janeiro, 23 out. 1963.

PONTUAL, Roberto. Lygia Clark: a fantasmática do corpo. Jornal do Brasil, Rio de Janeiro, 21 set. 1974.

SAVAGET, Edna. Caminhando de capacêtes vivenciais. A riquíssima Lígia veio de Minas - como não sobreviver de sua arte - as fabulosas ideias que atuam mais que ácido lisérgico. Jornal do Brasil, Caderno GB, n. 2, 1967.

\section{Fontes de Catálogos:}

BRETT, Guy. Lygia Clark: Seis Células. Lygia Clark. Trad. A. C. O Mundo de Lygia

Clark. Barcelona: Catálogo Fundação Antoni Tápies, p. 7, 1998.

Arte de Vanguarda e Terceiro Mundo. Art and Criticism. Trad. A. C. o Mundo de Lygia Clark. Winchester, p. 3, out. 1979.

BORJA-VILLEL, Manuel J. et al. Lygia Clark: catálogo. Barcelona, Fundació Antoni Tàpies, 21 out. - 21 dez. 1997 (espanhol/português).

CLARK, Lygia. Lygia Clark. Textos de Lygia Clark, Ferreira Gullar e Mário Pedrosa. Rio de Janeiro: FUNARTE, 1980. 
CLARK, Lygia. In: SCOVINO, Felipe e CLARK, Alessandra (Org.). O Mundo de Lygia Clark. Rio de Janeiro: Associação Cultural O Mundo de Lygia Clark, 2004.

et. al. Da obra ao acontecimento: somos o molde. A você cabe o sopro. Pinacoteca de São Paulo. Musée de Beaux Arts de Nantes, France, 2005.

et al. Lygia Clark. Barcelona/Rio de Janeiro: Fundació Antoni Tàpies e Paço Imperial, 1999. (Catálogo da Exposição Lygia Clark).

. Catálogo da Fundação Antoni Tàpies. Trad. e $\overline{\text { arquivo }}$ da A. C. O Mundo de Lygia Clark. Rio de Janeiro: Navilouca, 1975.

HERKENHOFF, Paulo. A aventura planar de Lygia Clark: de caracóis, escadas e caminhando. In: CLARK, Lygia. Lygia Clark. São Paulo: MAM, p. 7-57, 1999.

NOVA Objetividade Brasileira. Rio de Janeiro: Museu de Arte Moderna do Rio de Janeiro, 1967.

Lygia Clark: The Abandonment of Art, 1948-1988. Cornelia Butler and Luis Pere Oramas, 2014. 